\title{
Dihydrotestosterone Therapy
}

National Cancer Institute

\section{Source}

National Cancer Institute. Dihydrotestosterone Therapy. NCI Thesaurus. Code C41474.

Any therapeutic procedure that administers dihydrotestosterone, often transdermally, as androgen replacement therapy. Dihydrotestosterone therapy is intended to activate various biochemical processes that are dependent on the steroid. 